\title{
The association between tuberculosis and the development of insulin resistance in adults with pulmonary tuberculosis in the Western sub-district of the Cape Metropole region, South Africa: a combined cross- sectional, cohort study
}

\author{
Lauren Philips ${ }^{1 *}$, Janicke Visser ${ }^{1}$, Daan $\mathrm{Nel}^{2}$ and Renée Blaauw ${ }^{1}$
}

\begin{abstract}
Background: The existence of a bi-directional relationship between tuberculosis (TB) and insulin resistance (IR)/ diabetes has been alluded to in literature. Although diabetes has been linked to increased tuberculosis risk, the relationship between tuberculosis as a causative factor for IR remains unclear. The study aimed to determine if an association existed between tuberculosis and IR development in adults with newly diagnosed pulmonary tuberculosis at baseline. It was additionally aimed to document changes in IR status during TB follow-up periods.

Methods: This cross-sectional study evaluated ambulatory participants at baseline for IR prevalence via anthropometry, biochemistry and diagnostic IR tests [homeostasis model assessment-IR (HOMA-IR) and quantitative insulin sensitivity check index (QUICKI)]. A prospective cohort sub-section study was additionally performed on approximately half of the baseline study population, who were followed-up at two and five months whilst on tuberculosis treatment. Summary statistics, correlation co-efficients and appropriate analysis of variance were used to describe and analyse data. Participants were excluded if they presented with other forms of tuberculosis, were HIV-positive, obese or had any pre-disposing IR conditions such as diabetes or metabolic syndrome.

Results: Fifty-nine participants were included from August 2013 until December 2014 (33.95 \pm 12.02 years old; 81. $4 \%$ male). IR prevalence was $25.4 \%$ at baseline, determined by a calculated HOMA-IR cut-off point of 2.477 . Patients with IR were younger $(p=0.04)$. Although the difference between IR levels in participants between baseline and follow-up was not significant, a decrease was observed over time. The majority of participants (61.0\%) presented with a normal BMI at baseline. Mean baseline values of fasting glucose were within normal ranges $(4.82 \pm 0$. $80 \mathrm{mmol} / \mathrm{L})$, whereas increased mean CRP levels $(60.18 \pm 50.92 \mathrm{mg} / \mathrm{L})$ and decreased mean HDL-cholesterol levels (males: $0.94 \pm 0.88 \mathrm{mmol} / \mathrm{L}$; females: $1.14 \pm 0.88 \mathrm{mmol} / \mathrm{L}$ ) were found.

Conclusions: The study found an association between tuberculosis and IR development in newly diagnosed pulmonary tuberculosis patients. Although not significant, IR levels decreased over time, which could be indicative of a clinical improvement. A high prevalence of IR amongst young tuberculosis patients therefore highlights the need for early identification in order to facilitate a reversal of IR and prevent possible IR-related complications.
\end{abstract}

Keywords: Pulmonary tuberculosis, Insulin resistance, Adults, HOMA-IR, QUICKI

\footnotetext{
*Correspondence: laurenp@sun.ac.za

'Division of Human Nutrition, Faculty of Medicine and Health Sciences,

Stellenbosch University, Cape Town, South Africa

Full list of author information is available at the end of the article
} 


\section{Background}

The existence of a bi-directional relationship between tuberculosis (TB) and insulin resistance (IR)/diabetes has previously been alluded to in the literature. Although diabetes has been linked to an increased risk for TB development, the role of TB as a causative factor for development of IR remains unclear. Insulin resistance is often defined as a condition where the body cells become resistant to the effects of insulin [1-4], resulting in a larger than normal insulin release to maintain a normal glycaemic response in the body [5]. Insulin resistance has previously been postulated to have either a genetic or environmental causation [6] and has been implicated in the aetiology of several diseases/conditions, such as the metabolic syndrome, cardiovascular disease, polycystic ovarian syndrome, hypertension, type 2 diabetes mellitus and obesity [6-9]. Although accurate diagnosis and measurement of IR is currently challenging, the estimated global prevalence ranges from 20 to $40 \%$ in the general population $[10,11]$.

It has been hypothesised that stress resulting from a long-term infection, such as TB or HIV, could increase the occurrence of IR in the body [12-14]. Recent literature has also described occurrences of impaired glucose tolerance, distortions in carbohydrate metabolism and altered insulin action among newly diagnosed TB patients [15-17]. The pro-inflammatory response accompanying a period of infection is postulated to result in decreased insulin production, which leads to a hyperglycaemic state [12]. This process may also be accompanied by the release of certain stress hormones such as epinephrine, cortisol and glucagon, which further impair the action of insulin [13]. The phenomenon of 'transient hyperglycaemia' (subsiding of glucose intolerance upon diagnosis after active TB treatment) can also not be discounted $[18,19]$. The effect of Rifampicin, one of the pharmaceutical agents used in the treatment of $\mathrm{TB}$, has also been found to result in transient hyperglycaemia soon after treatment commencement due to its strengthening of intestinal glucose absorption [20]. Furthermore, according to Schwartz's theories, it has been postulated that the pancreas could be assaulted by TB either via concomitant pancreatitis (resulting in heightened susceptibility to inflammation and/or amyloidosis) or via the forced habitation of the pancreas $[21,22]$. Moreover, the persistence of TB bacteria in adipose tissue has been thought to be a possible causative factor for systemic IR [23].

To the author's knowledge, there are no published studies documenting IR prevalence in pulmonary tuberculosis (PTB) patients using HOMA-IR and QUICKI tests. Given the high prevalence of both communicable and noncommunicable diseases in South Africa, it was considered prudent to investigate the relationship between the two morbidities in a developing country setting. The study therefore aimed to determine if an association existed between TB and IR development in ambulatory adults with newly diagnosed PTB through the use of HOMA-IR and QUICKI. It was additionally aimed to document changes in IR status during follow-up. Once IR participants were identified, it was intended to document any differences between the IR and non-IR groups.

\section{Methods}

\section{Study population}

A descriptive, cross-sectional study was undertaken and participants were enrolled from the Albow Gardens clinic in the Western sub-district of the Cape Metropole region (South Africa) from August 2013 until December 2014. Recruitment was done via non-random, purposive sampling and participants were included in the study if they were newly diagnosed with PTB (either via molecular, microbiological or radiographical testing), were between the ages of 18-65 years old, on a standardised TB treatment regime, HIV-negative and willing to provide a blood sample. Participants were excluded if they presented with any other forms of tuberculosis, were HIV-positive, had increased anthropometrical values [obese (BMI $\geq 30 \mathrm{~kg}$ / $\mathrm{m}^{2}$ ) or increased waist circumference measurement (males $>102 \mathrm{~cm}$; females $>88 \mathrm{~cm}$ )] or had any pre-disposing IR conditions (such as diabetes or metabolic syndrome). Once participants had been identified for participation in the cross-sectional study, approximately half $(n=29)$ were selected to be followed up at two and five months after tuberculosis treatment commencement by means of a prospective cohort sub-section study.

The study was approved by the Health Research Ethics Committee of the Faculty of Medicine and Health Sciences, Stellenbosch University in October 2012 (S12/ 08/227). Permission was also granted (April 2013) by the City of Cape Town (CoCT) to recruit participants from the Albow Gardens clinic (ref number:10346). Participants were required to give written informed consent prior to data collection. Privacy of participants for the duration of the study was ensured by making use of an anonymous approach.

\section{Anthropometry}

The weight (calibrated, beam-balance scale) and height (fixed stadiometer) of each participant was measured at baseline according to standardised techniques [24]. The Body Mass Index (BMI) of each participant was subsequently calculated and classified according to the formula: Weight $(\mathrm{kg}) /$ height $(\mathrm{m})^{2}$ [25]. The waist and hip circumferences were measured using a non-stretchable tape measure and were also performed using standardised techniques [24]. The waist: hip ratio was calculated using the formula: waist circumference (cm)/hip circumference $(\mathrm{cm})$ and classified according to the 
World Health Organisation (WHO) cut-off points [26]. Four skinfold measurements were taken, namely biceps, triceps, subscapular and suprailieac, according to standardised techniques for these measurements. A reliable skinfold calliper (Harpenden) was used to perform all measurements. Fat mass, fat free mass and body fat percentage were then calculated based on the sum of skinfold measurements and classified accordingly. The average of three measurements was taken for weight, height, waist and hip circumferences, as well as skinfold measurements. Only the height was measured at baseline, whilst all remaining anthropometrical measurements were performed at all follow-up visits.

\section{Biochemistry}

A maximum of $15 \mathrm{ml}$ of blood was collected from each participant, after a 10-h overnight fast. Samples were taken by a trained nursing sister at the data collection site and transported under correct storage conditions to the laboratory of the National Health Laboratory Services (NHLS). Albumin (bromocresol green solution), fasting glucose, C-reactive protein (CRP) and lipid profile were analysed using the Siemens Advia 1800. With regard to the lipid profile, total cholesterol was analysed using an enzymatic method, whilst the triglyceride value was calculated using the Fossati three-step enzymatic reaction. LDL-cholesterol was determined by means of the Friedewald formula [27]. The white cell count was performed by the Siemens Advia 2120 whilst fasting insulin was analysed with the help of ADVIA Centaur ${ }^{\circ}$ Insulin Lite Reagent and Solid Phase. Standardised reference ranges of the NHLS were used to classify biochemical values.

\section{Diagnostic IR-tests}

The HOMA-IR diagnostic test was performed according to the following formula: [Fasting serum insulin $(\mu \mathrm{U} / m l) x$ fasting plasma glucose (mmol/L)]/22.5 [28]. The QUICKI measurement is the inverse logarithm of the HOMA-IR calculation, namely: $1 /[\log$ (fasting insulin $\mu \mathrm{U} / \mathrm{ml}$ ) $+\log$ (fasting glucose $m g / d L] ~[29]$. As there is currently no standardised cut-off point for either the HOMA-IR or the QUICKI measurement, the data generated by this study was used to calculate a relevant HOMA-IR cut-off point. This was based on the lower limit of the upper quartile (P75), as has been performed in similar studies [30-33]. Once the HOMA-IR cut-off had been calculated, the corresponding QUICKI value was determined by means of a receiver operating characteristic (ROC) curve analysis. Any individual having a HOMA-IR value greater than the calculated cut-off point, as well as below the QUICKI cutoff point, was classified as having possible IR. The HOMA-IR was used as the primary tool for identifying IR and the QUICKI was calculated to reinforce or compare results.

\section{Statistical analysis}

Statistical analysis was performed using STATISTICA version 12 [StatSoft Inc. (2014)] and Microsoft Excel 2010. Summary statistics were used to describe data. Results were expressed as mean \pm standard deviation. Regression and correlation analysis were utilised to document the relationship between continuous variables. Appropriate analysis of variance was used to investigate relations between continuous variables and nominal variables, whilst Bootstrap procedures were used in cases where the residuals were not normally distributed. For variables measured repeatedly over time, repeated measures ANOVA were done with the compound symmetry assumption on the correlation structure over time. ROC curves were performed to calculate the corresponding QUICKI cut-off point at baseline. A $p$-value of $p<0.05$ represented statistical significance in hypothesis testing and $95 \%$ confidence intervals were used to describe the estimation of unknown parameters. The power analysis was done to estimate the sample size of participants needed at baseline $(n=30)$ and those seen at two and five months $(n=29)$. A power of $90 \%$ was able to detect a medium effect size of 0.6 .

\section{Results}

Fifty-nine participants were recruited during the 17 month data collection period. A flow diagram indicating the inclusion of study participants is shown in Fig. 1. The majority of patients were male $(81.4 \%)$ and had a mean age of $33.95 \pm 12.02$ years.

\section{Anthropometry}

The majority of participants $(n=36,61.0 \%)$ had a baseline BMI in the normal range according to WHO cut-off points $\left(18.50-24.99 \mathrm{~kg} / \mathrm{m}^{2}\right)$ [25], while $33.9 \%(n=20)$ had a BMI of $<18.5 \mathrm{~kg} / \mathrm{m}^{2}$, classifying them with varying levels of underweight. All of the anthropometrical measurements experienced a significant increase over time $(p<0.05)$, except for the biceps skinfold (Table 1). These increases occurred mainly in the first two months after treatment commencement.

\section{Biochemistry}

Baseline biochemistry results showed that the majority of patients $(n=50 ; 84.7 \%)$ had an increased mean CRP level $(60.18 \pm 50.92 \mathrm{mg} / \mathrm{L})$ and decreased mean HDLcholesterol level $(n=41 ; 69.5 \%)$ at baseline (males: $0.94 \pm 0.88 \mathrm{mmol} / \mathrm{L}$; females: $1.14 \pm 0.88 \mathrm{mmol} / \mathrm{L})$. Mean fasting glucose $(4.82 \pm 0.80 \mathrm{mmol} / \mathrm{L})$, fasting insulin $(11.37 \pm 19.20 \mathrm{mU} / \mathrm{L})$, albumin $(39.32 \pm 4.35 \mathrm{~g} / \mathrm{L})$ and white cell count $\left(8.84 \pm 3.5610^{\wedge} 9 / \mathrm{L}\right)$ were all in the normal reference ranges. According to fasting glucose levels at baseline, 1.7\% $(n=1)$ and 3.4\% $(n=2)$ of participants could be classified as having impaired 


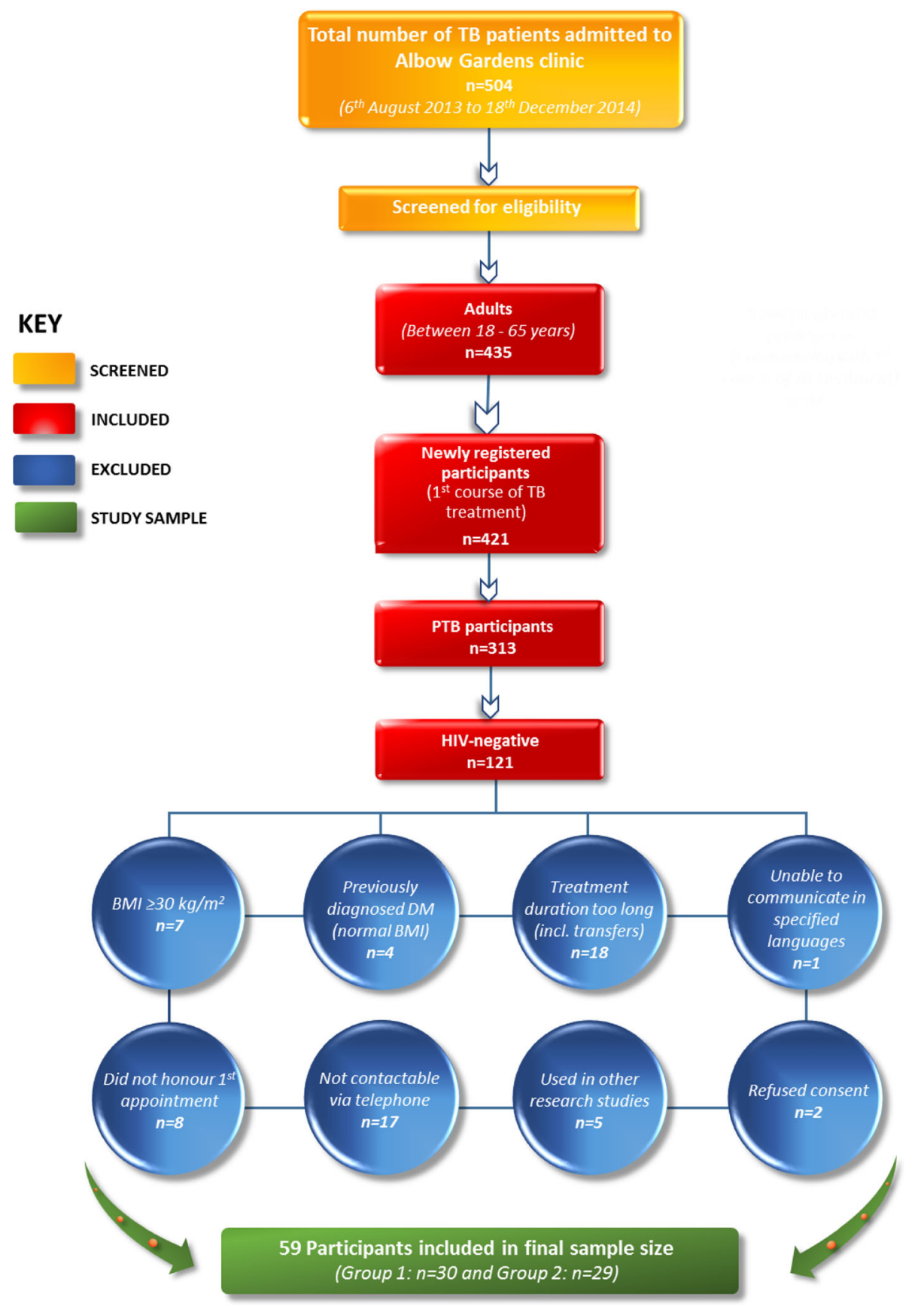

Fig. 1 Flow diagram for inclusion of study participants. Group 1 = Participants seen at baseline only; Group 2 = Participants seen at baseline, two and five months; TB = tuberculosis; PTB = pulmonary tuberculosis; HIV = human immunodeficiency virus; BMI = Body Mass Index; DM = diabetes mellitus

fasting glucose (IFG) $(6.1 \mathrm{mmol} / \mathrm{L}-6.9 \mathrm{mmol} / \mathrm{L})$ and diabetes $(\geq 7 \mathrm{mmol} / \mathrm{L})$ respectively [34].

Significant changes over time were seen with a decrease in both CRP $(<0.001)$ and white cell count levels $(<0.001)$, while albumin experienced an increase $(<0.001)$. Total, LDL and HDL-cholesterol experienced a significant increase in the first two months of treatment, followed by a tapering off between two and five months (Table 1).

\section{Insulin resistance}

The 75th percentile of the HOMA-IR was calculated using data collected from participants (cut-off value of 2.477). A corresponding QUICKI cut-off point was calculated on the basis of the HOMA-IR and a value of 0.336 was obtained. Using this information, 25.4\% $(n=15)$ participants were classified with IR at baseline (Fig. 2). Participants with postrecruitment possible metabolic syndrome [according to 
Table 1 Changes in anthropometrical and biochemical variables over time with repeated measures ANOVA in follow-up group $(n=29)$

\begin{tabular}{|c|c|c|c|c|c|c|}
\hline Variable & Unit & $\begin{array}{l}\text { ANOVA } \\
\text { (F-test) }\end{array}$ & $\begin{array}{l}\text { Baseline } \\
\text { Mean (SD) }\end{array}$ & $\begin{array}{l}\text { Two months } \\
\text { Mean (SD) }\end{array}$ & $\begin{array}{l}\text { Five months } \\
\text { Mean (SD) }\end{array}$ & $p$-value \\
\hline \multicolumn{7}{|l|}{ Anthropometry } \\
\hline Weight & kg & $F(2,56)=39.51$ & $56.83(10.66)$ & $59.76(11.65)$ & $61.37(11.26)$ & $<0.001$ \\
\hline BMI & $\mathrm{kg} / \mathrm{m}^{2}$ & $F(2,56)=39.34$ & $19.65(2.62)$ & $20.66(2.93)$ & $21.21(2.68)$ & $<0.001$ \\
\hline Waist circumference & $\mathrm{cm}$ & $F(2,56)=38.44$ & $70.38(8.84)$ & $72.95(9.32)$ & $75.40(9.18)$ & $<0.001$ \\
\hline Waist:hip ratio & - & $F(2,56)=36.29$ & $0.83(0.08)$ & $0.85(0.09)$ & $0.88(0.09)$ & $<0.001$ \\
\hline Biceps skinfold & $\mathrm{mm}$ & $F(2,56)=1.81$ & $3.16(1.45)$ & $3.36(1.96)$ & $3.49(2.02)$ & 0.174 \\
\hline Triceps skinfold & $\mathrm{mm}$ & $F(2,56)=10.05$ & $7.01(4.05)$ & $7.49(4.29)$ & $8.13(4.63)$ & $<0.001$ \\
\hline Subscapular skinfold & $\mathrm{mm}$ & $F(2,56)=10.22$ & $7.77(2.85)$ & $8.26(2.69)$ & $8.79(3.35)$ & $<0.001$ \\
\hline Suprailiac skinfold & $\mathrm{mm}$ & $F(2,56)=6.81$ & $6.10(4.61)$ & $7.32(5.50)$ & $7.57(5.11)$ & 0.002 \\
\hline Sum of skinfolds & $\mathrm{mm}$ & $F(2,56)=8.64$ & 24.03 (11.79) & $26.43(13.47)$ & $27.99(14.18)$ & $<0.001$ \\
\hline Fat mass & kg & $F(2,56)=17.63$ & $7.22(4.34)$ & $8.38(4.39)$ & $8.73(4.50)$ & $<0.001$ \\
\hline Fat free mass & kg & $F(2,56)=38.11$ & $49.61(9.56)$ & $51.38(10.13)$ & $52.63(10.23)$ & $<0.001$ \\
\hline Percentage body fat & $\%$ & $F(2,56)=10.89$ & $12.58(6.53)$ & $13.85(5.96)$ & $14.19(6.31)$ & $<0.001$ \\
\hline \multicolumn{7}{|l|}{ Biochemistry } \\
\hline Albumin & $g / L$ & $F(2,56)=15.36$ & $39.97(4.06)$ & $42.55(3.90)$ & 43.41 (3.77) & $<0.001$ \\
\hline Fasting glucose & $\mathrm{mmol} / \mathrm{L}$ & $F(2,56)=2.11$ & $4.78(0.61)$ & $4.83(0.58)$ & $4.57(0.50)$ & 0.131 \\
\hline CRP & $\mathrm{mmol} / \mathrm{L}$ & $F(2,56)=21.63$ & $56.72(50.83)$ & $27.54(32.11)$ & $12.48(15.07)$ & $<0.001$ \\
\hline Fasting insulin & $\mathrm{mU} / \mathrm{l}$ & $F(2,56)=1.16$ & $14.62(25.98)$ & $11.91(15.81)$ & $8.99(6.77)$ & 0.320 \\
\hline Total cholesterol & $\mathrm{mg} / \mathrm{L}$ & $F(2,56)=10.43$ & $3.55(0.95)$ & $4.20(1.06)$ & $3.94(0.84)$ & $<0.001$ \\
\hline Triglycerides & $\mathrm{mmol} / \mathrm{L}$ & $F(2,56)=0.85$ & $0.85(0.30)$ & $0.93(0.38)$ & $0.89(0.38)$ & 0.432 \\
\hline HDL-cholesterol & $\mathrm{mmol} / \mathrm{L}$ & $F(2,56)=14.50$ & $0.99(0.30)$ & $1.30(0.46)$ & $1.31(0.38)$ & $<0.001$ \\
\hline LDL-cholesterol & $\mathrm{mmol} / \mathrm{L}$ & $F(2,56)=4.97$ & $2.17(0.75)$ & $2.48(0.87)$ & $2.22(0.70)$ & 0.010 \\
\hline White cell count & 10^9/L & $F(2,56)=16.30$ & $8.74(4.18)$ & $6.98(2.91)$ & $5.92(2.01)$ & $<0.001$ \\
\hline
\end{tabular}

$S D=$ standard deviation, $B M I=$ Body Mass Index, $C R P=C$-reactive protein, $H D L=$ high density lipoprotein, $L D L=$ low density lipoprotein Bold variables indicate statistical significance

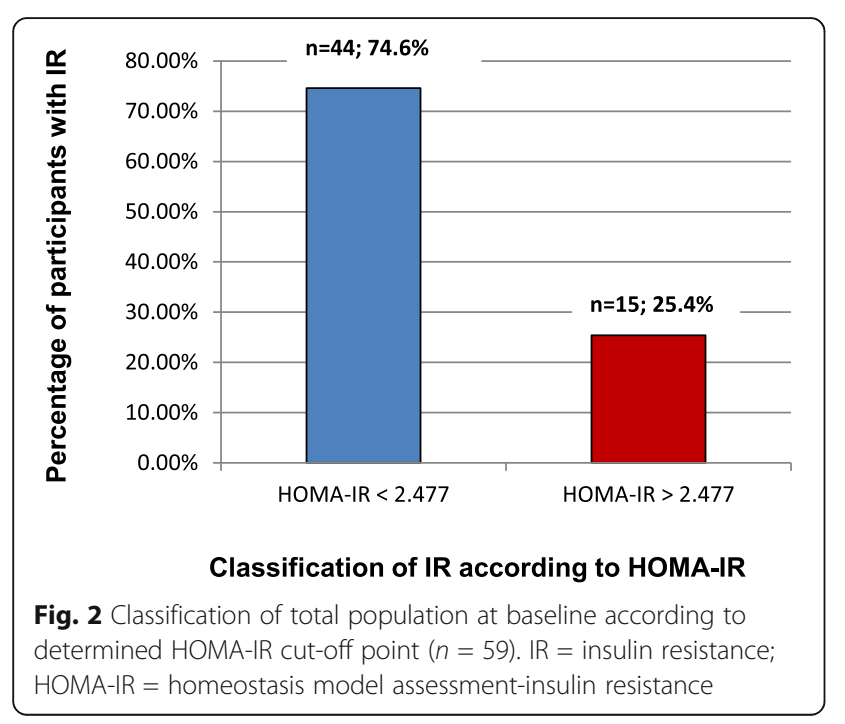

International Diabetes Federation (IDF) $(n=2)[2,35]$ and Adult Treatment Panel III (ATP III) $(n=1)$ [36] criteria] and diabetes $(n=2)$ were excluded in further subanalyses, which resulted in a minimal difference in overall prevalence rates of IR (IDF: 24.6\%; ATP III: 25.9\%; possible diabetes: $24.6 \%$ ).

Regression analysis showed the anthropometrical measurements of waist circumference $(r=0.507 ; p=0.011)$, sum of skinfolds $(r=0.353 ; p=0.039)$ and fat mass $(r=-2.419 ; p=0.08)$ were the best predictors of IR at baseline. Although the difference experienced between HOMA-IR levels in participants between baseline and follow-up periods was not significant $(p=0.311)$, a decrease was experienced over time (Fig. 3). Participants in the follow-up group $(n=29)$, showed a $31 \%$ prevalence of IR at baseline $(n=9)$, compared to $27.6 \%(n=8)$ and $20.7 \%(n=6)$ at two and five months respectively.

Insulin resistant vs. non-insulin resistant groups

Patients with IR were shown to be younger $(p=0.04)$ (Fig. 4) and had a higher fasting insulin measurement 


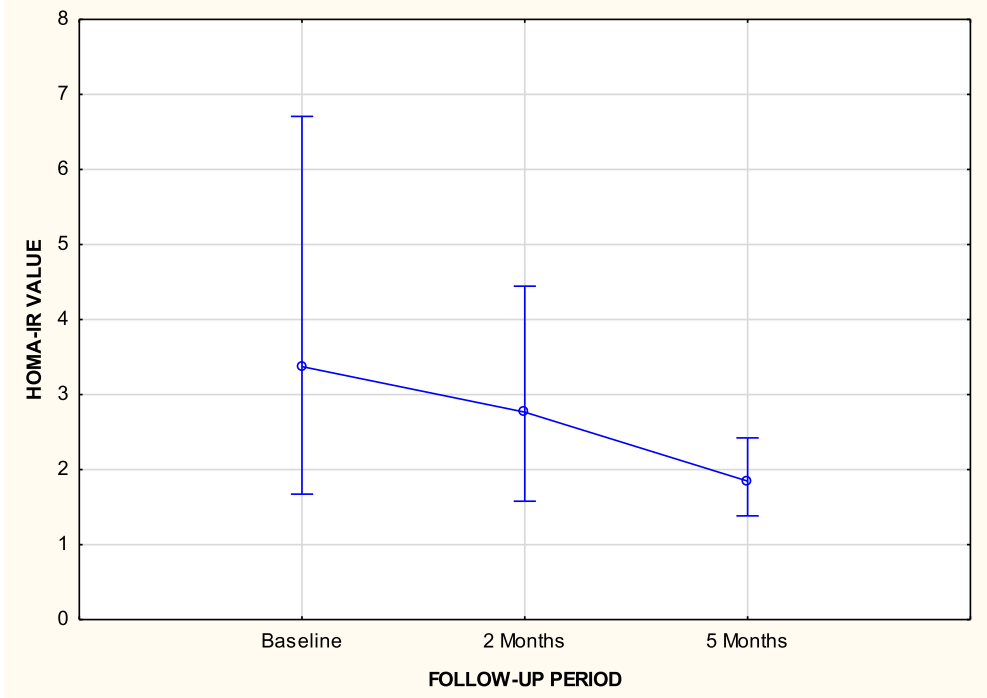

HOMA-IR = homeostasis model assessment-insulin resistance $(p=0.311)$

Fig. 3 Changes in HOMA-IR values of participants over five-month follow-up period $(n=29)$. HOMA-IR = homeostasis model assessment-insulin resistance

$(p<0.01)$. Despite no significance between the groups in terms of CRP levels, the IR group had a lower mean value $(p=0.51)$. There were also no significant differences between gender, age groups, race, BMI classification or waist circumference classification between IR and non-IR groups at baseline (Table 2). Upon consideration of differences between IR and non-IR groups at the two and five month follow-up visits, there were no significant results for any of the variables.

\section{Discussion}

Despite the mean BMI at baseline being classified in the normal range for both males and females, there was an overall prevalence of $33.9 \%$ of undernutrition (BMI $<18.5 \mathrm{~kg} / \mathrm{m}^{2}$ ) among the study population. These rates of undernutrition are in agreement with previously described rates of between $20 \%$ and $71.6 \%$ [37].

A low BMI at diagnosis has been linked to an increased risk of relapse [38] and demonstrates an indirectly

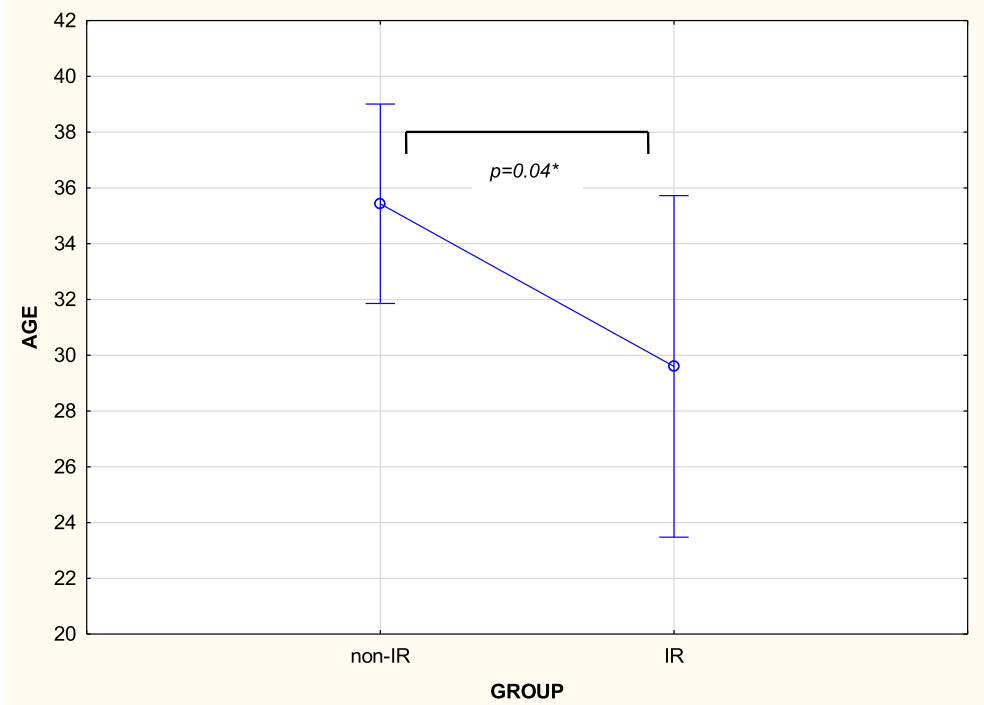

Fig. 4 Comparison between the IR and non-IR group vs. age of participants $(n=59)$. IR: insulin resistance. $p=0.04^{*}$. Mean (years) \pm SD: non-IRgroup (35.43 \pm 12.02$)$; IR group (29.60 \pm 11.29$)$ 
Table 2 Comparison of baseline variables of IR group vs. non-IR group (continuous and categorical variables) $(n=59)$

\begin{tabular}{|c|c|c|c|c|}
\hline Variable (Baseline) & Unit & $\begin{array}{l}\text { Non-IR Group }(n=44) \\
\text { Mean (SD) }\end{array}$ & $\begin{array}{l}\text { IR Group }(n=15) \\
\text { Mean (SD) }\end{array}$ & $p$-value* \\
\hline \multicolumn{5}{|l|}{ Continuous variables } \\
\hline Age & years & $35.43(12.02)$ & $29.60(11.29)$ & 0.04 \\
\hline Systolic blood pressure & $\mathrm{mmHg}$ & $119.23(17.78)$ & $125.13(11.57)$ & 0.13 \\
\hline Diastolic blood pressure & $\mathrm{mmHg}$ & $75.45(12.46)$ & $79.93(10.42)$ & 0.05 \\
\hline Albumin & $g / L$ & $38.75(4.58)$ & $41.00(3.16)$ & 0.17 \\
\hline Fasting glucose & $\mathrm{mmol} / \mathrm{L}$ & $4.71(0.69)$ & $5.13(1.02)$ & 0.16 \\
\hline CRP & $\mathrm{mmol} / \mathrm{L}$ & $64.10(53.82)$ & $48.91(41.01)$ & 0.51 \\
\hline Fasting insulin & $\mathrm{mU} / \mathrm{l}$ & $5.63(2.43)$ & $28.20(33.21)$ & $<0.01$ \\
\hline Total cholesterol & $\mathrm{mg} / \mathrm{L}$ & $3.39(0.87)$ & $3.71(0.95)$ & 0.30 \\
\hline Triglycerides & $\mathrm{mmol} / \mathrm{L}$ & $0.88(0.35)$ & $0.95(0.27)$ & 0.38 \\
\hline HDL-cholesterol & $\mathrm{mmol} / \mathrm{L}$ & $0.99(0.33)$ & $0.93(0.26)$ & 0.56 \\
\hline LDL-cholesterol & $\mathrm{mmol} / \mathrm{L}$ & $1.98(0.65)$ & $2.35(0.80)$ & 0.24 \\
\hline White cell count & $10^{\wedge} 9 / 1$ & $8.79(3.68)$ & $8.99(3.30)$ & 0.68 \\
\hline HOMA-IR & - & $1.18(0.54)$ & $7.22(10.32)$ & $<0.01$ \\
\hline \multirow[t]{3}{*}{ QUICKI } & - & $0.39(0.04)$ & $0.31(0.03)$ & $<0.01$ \\
\hline & & Categorical variables & & \\
\hline & & Groups assessed & & $p$-value ${ }^{* * *}$ \\
\hline Gender & & IR vs. non-IR & & 0.877 \\
\hline Age groups** & & IR vs. non-IR & & 0.210 \\
\hline Race & & IR vs. non-IR & & 0.816 \\
\hline BMI classification & & IR vs. non-IR & & 0.217 \\
\hline Waist circumference classification & & IR vs. non-IR & & 0.122 \\
\hline
\end{tabular}

$S D=$ standard deviation, $C R P=C$-reactive protein, $H D L=$ high density lipoprotein, $L D L=$ low density lipoprotein, $H O M A-I R=$ homeostasis model assessmentinsulin resistance, $Q U I C K I=$ quantitative insulin sensitivity check index

Bold and shaded variables indicate statistical significance

*Mann-Whitney U test

**Age groups concerned: $18-30$ years; $31-45$ years; $46-65$ years

*** cc Maximum-likelihood chi square test

proportional relationship existing between BMI and mortality risk [39]. Previous studies have also indicated that the occurrence of undernutrition among TB patients cannot be solely attributed to the disease itself but rather to a multitude of contributing factors, such as extreme poverty, food insecurity and reduced health-seeking behaviour [40, 41].

The majority of anthropometrical measurements showed a significant increase whilst the patients were on treatment, with the greatest changes taking place during the intensive phase (first two months of treatment) [42]. However, some patients failed to gain more than $5 \%$ weight over the five-month period and/or remained in the underweight BMI category, thereby placing them at greater risk of treatment failure and/ or relapse at a later stage [38]. Overall weight gain of TB patients whilst on treatment is a common phenomenon [43-47] although some researchers are hesitant to use weight gain as a marker of successful response to treatment $[48,49]$.
Findings verifying low levels of albumin and high CRP levels in TB patients have been well documented in literature [50-54]. Baseline study results yielded an elevated mean CRP, while the mean albumin level was in the normal range. It is perhaps the raised CRP level that is more indicative of active TB disease because it has been described as a non-specific measure of systemic inflammation in the body [51]. The degree of CRP escalation has also been linked to the presence of weight loss and to disease severity, and this may increase levels even further [51]. The albumin levels were possibly not as severely affected due to the patients being relatively 'well' TB patients (i.e. with predominantly normal BMI's, not hospitalised, drug-resistant or HIV-co-infected).

A lowered total cholesterol level has previously been described in the literature $[51,55,56]$, in which it was hypothesised that prolonged persistence of the TB bacterium may result in cholesterol breakdown, especially in persons who had been infected latently for a period of 
time. Reduced HDL levels have been reported in numerous studies with various infectious or inflammatory conditions [57-59]. A study by Deniz et al. in 2007 showed lowered levels of HDL-cholesterol in their PTB-specific study population [56], which could be linked to the activated acute phase response (APR) often seen in TB disease [60-63].

The current study saw an increase in albumin levels, as well as a decrease in CRP (both over time). This would suggest a 'resolution' of the APR or a suppression of the inflammatory response [52], which is a phenomenon well reported in literature, both for albumin [64] and CRP [52-54, 64, 65]. There were, however, some patients in the follow-up group who still presented with a raised CRP at the five-month mark, which could perhaps indicate a suboptimal treatment response [53] or the presence of other infections, especially if the CRP did not show an overall downward trend. Total cholesterol, as well as LDL-and HDL-cholesterol, experienced a significant increase during the intensive treatment phase. There were however no significant differences between the two-and five-month periods. This is an unusual finding because one might expect the values to increase even more at the end of the follow-up period and warrants more investigation given the important role of adequate cholesterol levels in protection against the mycobacteria.

One individual in the current study was classified with IFG (1.7\%) and two with diabetes (3.4\%). A systematic review published by Jeon et al. in 2010 showed total DM prevalence in TB patients to fall between the range of $1.9 \%$ and $35 \%$ [66], but some of these were diagnosed only after development of TB. The two 'suspected' diabetic patients were, however, not confirmed as having diabetes. In a cross-sectional study conducted in West Africa, participants displayed a 5\% IFG and a $1.9 \%$ DM rate, which is comparable with the current study despite differing inclusion criteria [67]. A retrospective study performed in Sri Lanka found $7.1 \%$ preexisting DM among their study sample, as well as $20 \%$ IFG and 2\% DM rates (although lower fasting glucose cut-off values were used) [68]. These raised levels could also be attributed to the "stress/transient hyperglycaemia" phenomenon $[18,19,69,70]$, as well as the pro-inflammatory response $[12,13]$ and medication effects [20].

The HOMA-IR is one of the so-called 'fasting indices', which utilises fasting measurements of both glucose and insulin. The HOMA-IR has been used extensively in epidemiological research and as a routine measurement in clinical practice [71] and together with the QUICKI [29] has proved to be a very popular fasting index [28]. Although the current gold-standard method of diagnosing IR, the hyperinsulinaemic-euglycemic clamp (HEC), is very often the preferred diagnostic tool, the inherent study design did not lend itself to this particular technique, largely due to the time-consuming nature of the test and the fact that study participants were ambulatory outpatients. A notable drawback of the HOMA-IR and QUICKI is, however, the lack of a standardised cut-off point to identify individuals with IR. Previous studies have suggested that IR occurs between the HOMA-IR levels of 2.1 and $3.8[28,72]$, which is a vast range but in which the value of 2.477 calculated in this study fits comfortably. Using this calculated cut-off point, the IR prevalence at baseline among this study population was $25.4 \%$, which equates to one in four persons with newly diagnosed PTB having IR. These findings were echoed by the QUICKI. This prevalence rate falls within the proposed range of $20-40 \%$ IR in the general population, of whom the majority are healthy persons (i.e. do not have TB) $[11,71]$. Recent studies have duly reported high levels of hyperglycaemia, impaired glucose tolerance and DM in TB patients [12, 15-19, 66, 69, 70, 73-78].

The follow-up profiles of both HOMA-IR and QUICKI seemed to indicate an improvement in IR over time. Although there were no significant differences noted between any of the time frames, there was an overall downward pattern with the HOMA-IR and an upward curve for the QUICKI, both signifying a 'lessening' of the IR state. This ties in closely with an improved and diminishing inflammatory response, as demonstrated with the improved CRP, albumin and white cell count. This could also be due to the well-described 'stress or transient' hyperglycaemia seen to occur in the early stages after TB diagnosis and which often resolves with progression of treatment $[18,19,73]$. Despite the largely improved IR status over the five-month follow-up period, two participants who had normal HOMA-IR and QUICKI values at baseline subsequently developed IR at two and five months, and two patients redeveloped IR at five months after originally presenting with it at baseline. This contests the stress hyperglyacemia hypothesis, as well as the improvement of an inflammatory state, and is an interesting phenomenon to be pursued.

The development of IR has often been linked to the process of aging $[29,79]$, since age progression is generally associated with greater gains in body weight and/or fat mass, especially in the central area of the body [80], as well as with an increased prevalence of chronic diseases of the lifestyle, including metabolic syndrome [81, 82]. As the younger patients in this study displayed a greater prevalence of IR, this could signal the need for increased awareness of greater disease potential among the more youthful TB population, despite contrasting results to date. Recent research has indicated the possibility of genetic influences on the development of IR, although at the present moment, minimal variants have been associated herewith [83]. 
There is generally a greater risk of IR with increasing anthropometrical measurements [84], and positive correlations have been documented between IR and BMI $[85,86]$, waist and hip circumference, body fat content and weight gain $[87,88]$. Several of these were seen in the current study (i.e. percentage body fat) and could perhaps be indicative of the phenomenon of increasing anthropometric measurements. A study conducted in 2012 by Addo et al. among adolescents in the United States showed that skinfolds (tricep and subscapular) were able to identify individuals at risk of developing IR [89]. The sum of skinfolds could perhaps be used as a marker to identify those at risk of developing IR, which may be prudent in populations that do not exhibit typical metabolic syndrome-like characteristics.

Because IR is largely termed an 'inflammatory' condition, levels of CRP (a positive acute phase protein) are often raised [90]. The inflammation typically found in IR is more of a 'low-grade' inflammatory state, which is often the result of the production of cytokines from visceral adipose tissue (VAT) [91]. The CRP levels are often produced as a response to the release of various cytokines designed to enable the inflammatory response [92]. One might thus have expected the CRP levels of the IR participants to be higher than the non-IR group, given the inflammatory nature of IR itself, its relationship with the APR and the fact that TB patients generally have increased CRP levels. However, the converse was seen. Given the fact that patients included in this study did not fit the conventional 'metabolic syndrome' or obesity profile, it could be speculated that they may have slightly higher levels of subcutaneous fat, compared with visceral tissue, which would, therefore, render a slightly less inflammatory profile, and this could have an inhibitory effect on CRP levels in the blood.

Leptin, an adipokine, has recently come under scrutiny regarding its role as a regulator of the immune system, as well as its effect on appetite [93] and IR reduction [94]. Findings regarding leptin levels in TB have to date been conflicting, with some studies showing higher leptin levels in TB patients [95-97] and others showing lower levels [98-101]. Individuals with reduced leptin concentrations have experienced an increased body weight over a short time duration, [102] which may be prudent in further investigating the link between TB and IR.

Recommendations for clinical practice include the implementation of integrative bi-directional screening (TB and $\mathrm{DM}$ ) in health care facilities, as well as close monitoring of $\mathrm{TB}$ patients presenting with hyperglycaemia upon treatment commencement. Vulnerable patients with an undesirable anthropometrical, biochemical or clinical presentation should also be referred timeously for nutritional support, preferably during the intensive phase of treatment. Regarding future research avenues, it would be prudent to assess IR prevalence in other susceptible TB populations (HIV-co-infected, extra-pulmonary patients and different life stages) as well as to utilise additional IR diagnostic tools. Re-assessment of patients who developed IR at the five-month mark may also yield valuable results once treatment is completed. Although it was not possible in this study, a desired outcome could be the determination of a specific biomarker cut-off (e.g. CRP) that would be able to identify IR in TB patients and largely act as a diagnostic tool.

Limitations of the study included the paucity of standardised reference values for HOMA-IR and QUICKI, as well as issues surrounding the reliability of the fasting insulin measurement. It was furthermore unclear whether patients presented with hyperglycaemia before study recruitment. Logistical issues such as the stipulated time of data collection (as IR is reportedly higher in the morning), patients already having commenced with TB treatment, use of a single recruitment site, compliance with overnight fasting guidelines and inherent aspects of the study design (including sample size) could also be viewed as limitations.

\section{Conclusion}

This study found an association between TB and IR development in newly diagnosed PTB patients, with one in four patients having IR. This high prevalence rate in the study population signals the need for early identification, especially in the younger and more vulnerable TB population, in order to facilitate a possible reversal of IR and prevent future IR-related complications.

\footnotetext{
Abbreviations

APR: Acute phase response; ATP III: Adult Treatment Panel III; BMI: Body Mass Index; CoCT: City of Cape Town; CRP: C-reactive protein; DM: Diabetes mellitus; HDL: High density lipoprotein; HEC: Hyperinsulinaemic-euglycemic clamp; HIV: Human immunodeficiency virus; HOMA-IR: Homeostasis model assessment-insulin resistance; IDF: International Diabetes Federation; IFG: Impaired fasting; IR: Insulin resistance; LDL: Low density lipoprotein; NHLS: National Health Laboratory Services; PTB: Pulmonary tuberculosis; QUICKI: Quantitative insulin sensitivity check index; ROC: Receiver operating characteristic; SD: Standard deviation; TB: Tuberculosis; VAT: Visceral adipose tissue; WHO: World Health Organisation
}

\section{Acknowledgements}

The authors would like to acknowledge the South African Medical Research Council (SAMRC) as a funding source for this project. Gratitude is also extended to Professor Peter Donald and Dr. Florian Von Groote-Bidlingmaier for their input from the conceptual stages of the project, as well as the management and staff of the TASK team at Brooklyn Chest Hospital and Albow Gardens Clinic.

\section{Funding}

LP was funded by the National Health Scholars Programme (NHSP) of the SAMRC. Additional funding was secured from the Harry Crossley Foundation and National Research Foundation (NRF). Funding from the SAMRC was purely for scholarship purposes, and other funding served to conduct the study (data collection costs). None of the above funding bodies participated in study design, data collection, analysis or interpretation of results, or manuscript preparation. 


\section{Availability of data and materials}

Please note that due to Stellenbosch University embargo's on raw data, this will not be deposited publicly. Interested individuals/parties are welcome to contact the author for more information concerning the raw data should any queries arise.

\section{Authors' contributions}

LP designed the study, collected and interpreted the data, drafted the manuscript. JV and RB assisted with study design and interpretation of data, revised the manuscript. DN analysed and interpreted the data, revised the manuscript. All authors read and approved the final manuscript.

\section{Ethics approval and consent to participate}

Mentioned under "Methods - Study population" in text.

[Health Research Ethics Committee of the Faculty of Medicine and Health Sciences, Stellenbosch University (S12/08/227)].

\section{Consent for publication}

Not applicable.

\section{Competing interests}

The authors declare that they have no competing interests.

\section{Publisher's Note}

Springer Nature remains neutral with regard to jurisdictional claims in published maps and institutional affiliations.

\section{Author details}

${ }^{1}$ Division of Human Nutrition, Faculty of Medicine and Health Sciences, Stellenbosch University, Cape Town, South Africa. ${ }^{2}$ Centre for Statistical Consultation, Stellenbosch University, Cape Town, South Africa.

\section{Received: 29 November 2016 Accepted: 1 August 2017} Published online: 15 August 2017

\section{References}

1. Mao F, Chen T, Zhao Y, et al. Insulin resistance: a potential marker and risk factor for active tuberculosis? Med Hypotheses. 2011;77(1):66-8.

2. International Diabetes Federation. The IDF consensus worldwide definition of the Metabolic Syndrome ([article online].2006. https://www.idf.org/ouractivities/advocacy-awareness/resources-and-tools/60:idfconsensusworldwide-definitionof-the-metabolic-syndrome.html. Accessed 10 Aug 2017.

3. Trout K, Homko C, Tkacs NC. Methods of measuring insulin sensitivity. Biol Res Nurs. 2007;8(4):305-18.

4. Cefalu WT, Leahy JL, Clark NG. Medical management of diabetes mellitus. New York; 2000. p. 57-75.

5. Mlinar B, Marc J, Janez A, Pfeifer M. Molecular mechanisms of insulin resistance and associated diseases. Clin Chim Acta. 2007;375(1-2):20-35.

6. Granberry MC, Fonseca VA. Insulin resistance syndrome: options for treatment. South Med J. 1999;92(1):2-15.

7. Reaven GM. Role of insulin resistance in human disease. Diabetes. 1988; 37(12):1595-607.

8. Ginsberg HN. Insulin resistance and cardiovascular disease. J Clin Invest. 2000;106(4):453-8.

9. Natali A, Ferrannini E. Hypertension, insulin resistance, and the metabolic syndrome. Endocrinol Metab Clin N Am. 2004;33(2):417-29.

10. Matsuda M, DeFronzo RA. Insulin sensitivity indexes obtained from oral glucose tolerance testing: comparison with the euglycaemic insulin clamp. Diabetes Care. 1999;22(9):1462-70.

11. Bonara E, Kiechl S, Willeit J, et al. Insulin resistance as estimated by homeostasis model assessment predicts incident symptomatic cardiovascular disease in Caucasian subjects from the general population: the Bruneck study. Diabetes Care. 2007;30(2):318-24.

12. Pickup JC. Inflammation and activated innate immunity in the pathogensis of type 2 diabetes. Diabetes Care. 2004;27(3):813-23.

13. Van Cromphaut S, Vanhorebeek I. D Berghe GV. Glucose metabolism and insulin resistance in sepsis. Curr Pharm Des. 2008;14(19):1887-99.

14. Blumenthal A, Isovski F, Rhee KY. Tuberculosis and host metabolism: ancient associations, fresh insights. Trans Res. 2009;154(1):7-14.
15. Bell L, Bhat V, George G, Awotedu AA, Gqaza B. Sluggish glucose tolerance in tuberculosis patients. SAMJ. 2007;97(5):374-7.

16. Karachunskiĭ MA, Balabolkin MI, Beglarian NR. Changes in carbohydrate metabolism in patients with tuberculosis. Vestn Ross Akad Med Nauk. 1995;7:18-21.

17. Hayashi S, Takeuchi M, Hatsuda K, et al. The impact of nutrition and glucose intolerance on the development of tuberculosis in Japan. Int J Tuberc Lung Dis. 2014;18(1):84-8.

18. Singh MM, Biswas SK, Ashok S, Ashok KR, Singh PP. Impaired glucose tolerance in active pulmonary tuberculosis. Indian J Tuberc. 1984;31(3):118-21.

19. Jawad F, Shem AS, Memon R, Ansari G. Glucose intolerance in pulmonary tuberculosis. J Pak Med Assoc. 1995;45(9):237-8.

20. Takasu N, Yamada T, Miura H, et al. Rifampicin-induced early phase hyperglycemia in humans. Am Rev Respir Dis. 1982;125(1):23-7.

21. Stock KP, Riemann JF, Stadler W, Rösch W. Tuberculosis of the pancreas. Endoscopy. 1981;13(4):178-80.

22. Broxmeyer L. Diabetes mellitus, tuberculosis and the mycobacteria: two millennia of enigma. Med Hypotheses. 2005;65(3):433-9.

23. Erol A. Visceral adipose tissue specific persistence of mycobacterium tuberculosis may be reason for the metabolic syndrome. Med Hypotheses. 2008;71(2):222-8.

24. Lee RD, Nieman DC. Nutritional Assessment. 3rd ed. New York: McGraw Hill; 2003.

25. World Health Organization. BMI classification. http://apps.who.int/bmi/index. jsp?introPage=intro_3.html. Accessed 25 May 2012.

26. World Health Organization. Waist circumference and waist: hip ratio. Geneva: Report of a WHO Expert Consultation; 2008. p. 8-11.

27. Friedewald WT, Levy RI, Fredrickson DS. Estimation of the concentration of low density lipoprotein cholesterol in plasma, without use of the preparative ultracentrifuge. Clin Chem. 1972;18:499-501.

28. Matthews D, Hosker J, Rudenski A, Naylor B, Treacher D, Turner R. Homeostasis model assessment: insulin resistance and $\beta$-cell function from fasting plasma glucose and insulin concentrations in man. Diabetologia. 1985;28:412-9.

29. Katz A, Nambi SS, Mather K, et al. Quantitative insulin sensitivity check index: a simple, accurate method for assessing insulin sensitivity in humans. J Clin Endocrinol Metab. 2000;85(7):2402-10.

30. Hedblad B, Nilsson P, Janzon L, Berglund G. Relation between insulin resistance and carotid intima-media thickness and stenosis in non-diabetic subjects. Results from a cross-sectional study in Malmo, Sweden. Diabetic Med. 2000;17(4):299-307.

31. Marques-Vidal $P$, Mazoyer $E$, Bongard $V$, et al. Prevalence of insulin resistance syndrome in southerwestern France and its relationship with inflammatory and hemostatic markers. Diabetes Care. 2002;25(8):1371-7.

32. Ascaso JF, Pardo S, Real JT, Lorente RI, Priego A, Carmena R. Diagnosing insulin resistance by simple quantitative methods in subjects with normal glucose metabolism. Diabetes Care. 2003;26(12):3320-5.

33. Lee $\mathrm{S}, \mathrm{Choi} \mathrm{S}$, Kim HJ, et al. Cutoff values of surrogate measures of insulin resistance for metabolic syndrome in Korean non-diabetic adults. J Korean Med Sci. 2006;21(4):695-700.

34. Amod A, Ascott-Evans BH, Berg Gl, et al. The 2012 SEMDSA guideline for the Management of Type 2 diabetes. JEMDSA. 2012;17(1):1-94.

35. Alberti KGMM, Zimmet P, Shaw J. Metabolic syndrome - a new world-wide definition. A consensus statement from the international diabetes federation. Diabetic Med. 2006;23(5):469-80.

36. Expert Panel on Detection, Evaluation and Treatment. Executive summary of the third report of the National Cholesterol Education Program (NCEP) expert panel on detection, evaluation and treatment of high blood cholesterol in adults (adult treatment panel III). JAMA. 2001;285(19):2486-97.

37. Hood MLH. A narrative review of recent progress in understanding the relationship between tuberculosis and protein energy malnutrition. Eur J Clin Nutr. 2013;67:1122-8.

38. Edwards LB, Livesay VT, Acquaviva FA, Palmer CE. Height, weight, tuberculosis infection, and tuberculous disease. Arch Environ Health. 1971;22(1):106-12.

39. Zachariah R, Spielmann MP, Harries AD, Salaniponi FM. Moderate to severe malnutrition in patients with tuberculosis is a risk factor associated with early death. Trans R Soc Trop Med Hyg. 2002;96(3):291-4.

40. Dodor EA. Evaluation of nutritional status of new tuberculosis patients at the Effia Nkwanta regional hospital. Ghana Med J. 2008;42(1):22-8.

41. Villamor E, Saathoff E, Mugusi F, Bosch RJ, Urassa W, Fawzi WW. Wasting and body composition of adults with pulmonary tuberculosis in relation 
to HIV-1 coinfection, socioeconomic status and severity of tuberculosis. Eur J Clin Nutr. 2006;60:163-71.

42. Directorate. TB DOTS Strategy Coordination, National Department of Health, Pretoria, South Africa. Department of Health, Republic of South Africa. National Tuberculosis Management Guidelines; 2014.

43. Schwenk A, Macallan D. Tuberculosis, malnutrition and wasting. Curr Opin Clin Nutr Metab Care. 2000;3(4):285-91.

44. Paton NI, Ng YM. Body composition studies in patients with wasting associated with tuberculosis. Nutrition. 2006;22(3):245-51.

45. PrayGod G, Range N, Faurholt-Jepsen D, et al. Weight, body composition and handgrip strength among pulmonary tuberculosis patients: a matched cross-sectional study in Mwanza, Tanzania. Trans R Soc Trop Med Hyg. 2011; 105(3):140-7.

46. Bhargava A, Chatterjee $M$, Jain $Y$, et al. Nutritional status of adult patients with pulmonary tuberculosis in rural central India and its association with mortality. PLoS One. 2013;8(10):e77979.

47. Frediani JK, Sanikidze E, Kipiani M, et al. Macronutrient intake and body composition changes during anti-tuberculosis therapy in adults. Clin Nutr. 2015. http://dx.doi.org/10.1016/j.clnu.2015.02.007.

48. Kennedy N, Ramsay A, Uiso L, Gutmann J, Ngowi Fl, Gillespie SH. Nutritional status and weight gain in patients with pulmonary tuberculosis in Tanzania. Trans R Soc Trop Med Hyg. 1996;90(2):162-6.

49. How SH, Kuan YC, Ng TH, Razali MR, Fauzi AR. Monitoring treatment response in sputum smear positive pulmonary tuberculosis patients: comparison of weight gain, sputum conversion and chest radiograph. Malays J Pathol. 2014;36(2):91-6.

50. Opolot JO, Theron AJ, Anderson R, Feldman C. Acute phase proteins and stress hormone responses in patients with newly diagnosed active pulmonary tuberculosis. Lung. 2015;193(1):13-8.

51. Sahin F, Yildiz P. Distinctive biochemical changes in pulmonary tuberculosis and pneumonia. Arch Med Sci. 2013;9(4):656.

52. Taha DA, Thanoon IAJ. Antioxidant status, C-reactive protein and iron status in patients with pulmonary tuberculosis. SQU Medical Journal. 2010;10(3):361-9.

53. Peresi E, Silva SM, Calvi SA, Marcondes-Machado J. Cytokines and acutephase serum proteins as markers of inflammatory regression during pulmonary tuberculosis treatment. J Bras Pneumol. 2008;34(11):942-9.

54. Bongiovanni $B$, Diaz $A$, D'Attilio $L$, et al. Changes in the immune and endocrine responses of patients with pulmonary tuberculosis undergoing specific treatment. Ann N Y Acad Sci. 2012;1262(1):10-5.

55. Gupta A, Shah A. Tuberculosis and diabetes: an appraisal. Ind J Tub. 2000;47(1):3-8.

56. Deniz O, Gumus S, Yaman H, et al. Serum total cholesterol, HDL-C and LDL$\mathrm{C}$ concentrations significantly correlate wtih radiological extent of disease and the degree of smear positively in patients with pulmonary tuberculosis. Clin Biochem. 2007;40(3):162-6.

57. Sammalkorpi K, Valtonen V, Kerttula Y, Nikkilä E, Taskinen MR. Changes in serum lipoprotein pattern induced by acute infections. Metab. 1988;37(9):859-65

58. Cabana VG, Siegel JN, Sabesin SM. Effects of the acute phase response on the concentration and density distribution of plasma lipids and apolipoporiteins. J Lipid Res. 1989:30:39-49.

59. Deniz O, Tozkoprana E, Yaman H, et al. Serum HDL-C levels, log (TG/HDL-C) values and serum total cholesterol/HDL-C ratios significantly correlate with radiological extent of disease in patients with community acquired pneumonia. Clin Biochem. 2006;39(3):287-92.

60. Tietge UJ, Maugeais C, Lund-Katz S, Grass D, de Beer FC, Rader DJ. Human secretory phospholipase A2 mediates decreased plasma concentrations of $\mathrm{HDL}-\mathrm{C}$ cholesterol and Apoa-l in response to inflammation in human Apoa-I transgenic mice. Arterioscler Thromb Vasc Biol. 2002;22(7):1213-8.

61. Artl A, Marsche G, Lestavel S, Sattler W, Malle E. Role of serum amyloid a during metabolism of acute-phase HDL-C by macrophages. Arterioscler Thromb Vasc Biol. 2000;20(3):763-72.

62. Miida T, Yamada T, Yamadera T, Ozaki K, Inano K, Okada M. Serum amyloid a protein generates Pre $\beta 1$ high-density lipoprotein from alpha-migrating high-density lipoprotein. Biochemist. 1999;38(51):16958-62.

63. Banka CL, Yuan T, de Beer MC, Kindy M, Curtiss LK, de Beer FC. Serum amyloid a (SAA): influence on HDL-C-mediated cellular cholesterol efflux. Lipid Res. 1999;36(5):1058-65.

64. De Moraes ML, de Paula RM, Delogo KN, et al. Association of serum levels of iron, copper and zinc, and inflammatory markers with bacteriological sputum conversion during tuberculosis treatment. Biol Trace Elem Res. 2014;160(2):176-84.

65. Lawn SD, Obeng J, Acheampong JW, Griffin GE. Resolution of the acutephase response in west African patients receiving treatment for pulmonary tuberculosis. Int J Tuberc Lung Dis. 2000;4(4):340-4.

66. Jeon CY, Harries AD, Baker MA, et al. Bi-directional screening for tuberculosis and diabetes: a systematic review. Tropical Med Int Health. 2010;15(11):1300-14.

67. Ade S, Affolabi D, Agodokpessi P, et al. Low prevalence of diabetes mellitus in patients with tuberculosis in Cotonou. Benin PHA. 2015;5(2):147-9.

68. Rajapakshe W, Isaakidis P, Sagili KD, et al. Screening patiens with tuberculosis for diabetes mellitus in Ampara. Sri Lanka PHA. 2015;5(2):150-2

69. Oluboyo PO, Erasmus RT. The significance of glucose intolerance in pulmonary tuberculosis. Tubercle. 1990;71(2):135-8.

70. Faurholt-Jepsen D, Range N, PrayGod G, et al. Diabetes is a risk factor for pulmonary tuberculosis: A case-control study from Mwanza, Tanzania. PloS ONE. 2011;6(8):1-5.(e24215).

71. Matsuda M. Measuring and estimating insulin resistance in clinical and research settings. Nutr Metab Cardiovasc Dis. 2010;20(2):79-86.

72. Monzillo LA, Hamdy O. Evaluation of insulin sensitivity in clinical practice and in research settings. Nutr Rev. 2003;61(12):397-412.

73. Kapur A, Harries AD. The double burden of diabetes and tuberculosis public health implications. Diabetes Res Clin Pract. 2013;101(1):10-9.

74. Başoğlu OK, Bacakoğlu F, Cok G, Sayiner A, Ateş M. The oral glucose tolerance test in patients with respiratory infections. Monaldi Arch Chest Dis. 1999;54(4):307-10.

75. Stevenson CR, Forouhi NG, Roglic G, et al. Diabetes and tuberculosis: the impact of the diabetes epidemic on tuberculosis incidence. BMC Public Health. 2007;7(1):234.

76. Viswanathan V, Kumpatla S, Aravindalochanan V, et al. Prevalence of diabetes and pre-diabetes and associated risk factors among tuberculosis patients in India. PLoS One. 2012;7(7):e41367.

77. Balakrishnan S, Vijayan S, Nair S, et al. High diabetes prevalence among tuberculosis cases in Kerala. India PLoS One. 2012;7(10):e46502.

78. Restrepo BI, Fisher-Hoch SP, Smith B, et al. Mycobacterial clearance from sputum is delayed during the first phase of treatment in patients with diabetes. Am J Trop Med Hyg. 2008;79(4):541-4.

79. DeFronzo RA, Tobin JD, Andres R. Glucose clamp technique: a method for quantifying insulin secretion and resistance. Am J Phys. 1979;237(3):214-23.

80. Ryan AS. Insulin resistance with aging. Sports Med. 2000;30(5):327-46.

81. Ford ES. Prevalence of the metabolic syndrome defined by the international diabetes federation among adults in the US. Diabetes Care. 2005;28(11):2745-9.

82. DeFronzo RA, Ferrannini E. Insulin resistance: a multifaceted syndrome responsible for NIDDM, obesity, hypertension, dyslipidemia, and atherosclerotic vascular disease. Diabetes Care. 1991:14(3):173-94.

83. Knowles JW, Xie W, Zhang Z, et al. Identification and validation of $\mathrm{N}$-acetyltransferase 2 as an insulin sensitivity gene. J Clin Invest. 2015;125(4):1739-51.

84. Simarro RM, Carbayo HJ, Massó OJ, et al. Association of insulin resistance with different anthropometric measures and cardiovascular risk factors in a non-diabetic popualation. Endocrinol Nutr. 2011;58(9):464-71.

85. Yeni-Komshian H, Carantoni M, Abbasi F, Reaven GM. Relationship beween several surrogate estimates of insulin resistance and quantification of insulin-mediated glucose disposal in 490 healthy nondiabetic volunteers. Diabetes Care. 2000;23(2):171-5.

86. Esteghamati A, Khalilzadeh O, Anvari M, Ahadi MS, Abbasi M, Rashidi A. Metabolic syndrome and insulin resistance significantly correlate with body mass index. Arch Med Res. 2008;39(8):803-8.

87. Gayoso-Diz P, Otero-Gonzalez A, Rodriguez-Alvarez MX, et al. Insulin resistance index (HOMA-IR) levels in a general adult population: curves percentile by gender and age. The EPIRCE study. Diab Res Clin Pract. 2011;94(1):146-55.

88. Grundy SM, Brewer HB Jr, Cleeman Jl, Smith SC Jr, Lenfant C. Definition of metabolic syndrome. Report of the National Heart, lung and blood institute/American Heart Association conference on scientific issues related to definition. Circulation. 2004;109(3):433-8.

89. Addo OY, Pereira MA, Himes JH. Is skinfold thickness as good as DXA when measuring adipositiy contributions to insulin resistance in adolescents? Am J Hum Bio. 2012;24(6):806-11. 
90. Jellinger PS. Metabolic consequences of hyperglycemia and insulin resistance. Insulin. 2009;4(1):2-14.

91. Yudkin JS, Stehouwer CDA, Emeis JJ, Coppack SW. C-reactive protein in healthy subjects: associations with obesity, insulin resistance, and endothelial dysfunction. A potential role for cytokines originating from adipose tissue? Arterioscler Thromb Vasc Biol. 1999;19(4):972-8.

92. Fonseca V, Desouza C, Asnani S, Jialal I. Nontraditional risk factors for cardiovascular disease in diabetes. Endocrinol Rev. 2004;25(1):153-75.

93. Lord GM, Matarese G, Howard JK, Baker RJ, Bloom SR, Lechler RI. Leptin modulates the T-cell immune response and reverses starvation-induced immuno-suppression. Nature. 1998:394(6696):897-901.

94. Berglund E, Vianna C, Donato J, et al. Direct leptin action of POMC neurons regulates glucose homeostasis and hepatic insulin sensitivity in mice. J Clin Invest. 2012;122:1000-9.

95. Zheng Y, Ma A, Wang Q, et al. Relation of leptin, ghrelin and inflammatory cytokines with body mass index in pulmonary tuberculosis patients with and without type 2 diabetes mellitus. PLoS One. 2013;8(11):e80122.

96. Yüksel I, Şencan M, Dökmetas HS, Dökmetas I, Ataseven H, Yönem O. The relation between serum leptin levels and body fat mass in patients with active lung tuberculosis. Endocr Res. 2003;29(3):257-64.

97. Çakir B, Yönem A, Güler S, et al. Relation of leptin and tumor necrosis factor alpha to body weight changes in patients with pulmonary tuberculosis. Horm Res. 1999;52(6):279-83.

98. Van Crevel R, Ottenhoff THM, van der Meer JWM. Innate immunity to Mycobacterium tuberculosis. Clin Microbiol Rev. 2002;15(2):294-309.

99. Van Lettow M, van der Meer JWM, West CE, van Crevel R, Semba RD. Interleukin-6 and human immunodeficiency virus load, but not plasma leptin concentration, predict anorexia and wasting in adults with pulmonary tuberculosis in Malawi. J Clin Endocrinol Metab. 2005;90(8):4771-6.

100. Schwenk A, Hodgson I, Rayner CF, Griffin GE, Macallan DC. Leptin and energy metabolism in pulmonary tuberculosis. Am J Clin Nutr. 2003;77(2):392-8.

101. Keicho N, Matsushita I, Tanaka T, et al. Circulating levels of adiponectin, leptin, fetuin-a and retinol-binding protein in patients with tuberculosis: markers of metabolism and inflammation. PLoS One. 2012;7(6):e38703.

102. Ravussin E, Pratley R, Maffei M, et al. Relatively llow plasma leptin concentrations precede weight gain in pima Indians. Nat Med. 1997;3:238-40.

\section{Submit your next manuscript to BioMed Central and we will help you at every step:}

- We accept pre-submission inquiries

- Our selector tool helps you to find the most relevant journal

- We provide round the clock customer support

- Convenient online submission

- Thorough peer review

- Inclusion in PubMed and all major indexing services

- Maximum visibility for your research

Submit your manuscript at www.biomedcentral.com/submit

) Biomed Central 